\title{
HISTÓRIA, REGULAC̣̃̃O E PODER DISCIPLINAR NO CAMPO DA SUPERVISÃO ESCOLAR
}

\author{
Adriana Bergold Leal* \\ Paula Corrêa Henning**
}

RESUMO: Este artigo tem como tema a supervisão escolar, sendo ela questionada por ângulos diferentes daqueles recorrentemente anunciados nas bibliografias específicas e até então raramente colocados sob suspeita. Como resultado das análises, problematiza a história da supervisão como uma narração linear que continua regulando o trabalho docente, mesmo negando essa função. Entendendo a regulação como uma forma de conduzir a ação docente, aproxima desta o conceito de poder disciplinar e os instrumentos de que, segundo Michel Foucault, esse poder faz uso para agir sobre os sujeitos: a vigilância hierárquica, a sanção normalizadora e o exame. Ressalta ainda a produtividade do fazer docente como justificativa da regulação provocada pela função supervisora. Interrompendo o curso natural da história da supervisão, é possível perceber que, embora pertencendo a ordens discursivas diferentes, as fases históricas narradas atendem à mesma estratégia de ação reguladora e ao mesmo solo epistêmico.

Palavras-chave: Supervisão Escolar; Poder Disciplinar; Estudos Pós-Estruturalistas.

\section{HISTORY, REGULATION AND DISCIPLINARY POWER IN THE SCHOOL SUPERVISION FIELD}

ABSTRACT: The presented article is about School Supervision, which is questioned by different angles from those announced again and again in specific bibliographies and until now rarely having been put under suspicion. As a result of the analysis, we problematize the history of supervision as a linear narrative that continues regulating the work of teaching, even denying this function. Regulation being understood as a way of conducting the act of teaching approximates, from this act of teaching, the concept of disciplinary power and the instruments which, according to Michel Foucault, are used by this power to act upon the individuals: hierarchical vigilance, normalizing sanction and exam. This study also emphasizes the productivity of teaching as a justification for the regulation provoked by the supervising function. When the natural course of supervision history is interrupted, it is possible for us to see that the historical phases narrated, even though belonging to different discursive orders, answer to the same strategy of regulating action and to the same epistemic ground.

Keywords: School Supervision; Disciplinary Power; Poststructuralist Studies.

\footnotetext{
* Licenciada em Pedagogia; Professora da Rede Pública Municipal de Novo Hamburgo. E-mail: adrigudy@gmail.com

* * Doutora em Educação pela Universidade do Vale do Rio dos Sinos (UNISINOS); Professora do Instituto de Educação e do Programa de Pós-Graduação em Educação Ambiental da Universidade Federal do Rio Grande (FURG). E-mail: paula.henning@ig.com.br
} 
Pretendendo analisar alguns dos discursos que vêm constituindo a supervisão escolar na contemporaneidade, este artigo concretiza, em partes, a vontade de enfocar os estudos sobre supervisão e seus efeitos discursivos com outros elementos até então não problematizados neste campo de saber. O texto aqui apresentado é um recorte de um trabalho de pesquisa desenvolvido pelo Centro Universitário Feevale, em Novo Hamburgo/RS. Para formar o corpus discursivo a ser analisado, optamos por trabalhar com quatro livros básicos mais indicados nos planos de ensino de disciplinas referentes à formação do supervisor escolar1.

Optamos por não dar ênfase a essas referências escolhidas como material de análise, pois, como Foucault (2006a) nos ajuda a entender, os discursos materializados nas obras dos autores não têm origem neles mesmos. Pertencem, sim, à lógica de pensamento dos campos de saber, neste caso o da supervisão escolar, nos quais os autores são capturados e sistematizam o que pode ou não ser dito.

Vivências e estudos sobre a supervisão escolar nos atravessaram e causaram efeitos. Efeitos de insatisfação com o já-sabido, com significações colocadas, por vezes, como verdades incontestadas. Pensando sobre elas, é possível dizer que a lógica do pensamento moderno incumbiu-se da tarefa de deixar as verdades do nosso mundo esquecidas como verdades que historicamente se formaram. É por isso que, pela via da curiosidade, voltamos a algumas delas referentes à supervisão para "tomá-las pelo avesso, e nelas investigar e destacar outras redes de significações" (CORAZZA, 2002, p. 111), dando-lhes outros sentidos.

É pela curiosidade que nos colocamos a pensar sobre a problemática recorrência de olhar para as coisas do mundo do mesmo jeito. $\mathrm{Na}$ tentativa de pensar o diferente, ainda que na contramão de muitas formas de pensamento, buscamos outras respostas para caminhos já problematizados. Assim, ao lançar nossos olhares sobre o material analisado, deparamo-nos com vários artigos abordando a história da supervisão escolar. Neles, os autores contam a trajetória da supervisão, traçando fases distintas da sua ação nas escolas, apontando erros e acertos da função e demarcando ações que são possíveis e as que não são possíveis de serem realizadas pelo profissional que exerce o respectivo papel. Devido à recorrência de alguns ditos, buscamos, em seus emaranhados, suas possíveis regularidades discursivas a partir do sentido que damos a eles e, assim, construímos a análise central deste texto: narração histórica linear da supervisão escolar. 
Analisando a abordagem expressa nos livros, apercebemo-nos dela em uma perspectiva de história linear e evolutiva, a qual busca a origem dos fatos e seu real conteúdo de verdade. Trata-se da bistória global, como diz Foucault, "que procura reconstituir a forma de conjunto de uma civilização, o princípio [...] de uma sociedade, a significação comum a todos os fenômenos de um período, a lei que explica sua coesão - o que se chama metaforicamente o 'rosto' de uma época" (FOUCAULT, 2002, p. 11, grifo do autor).

É a narração dos fatos passados registrados em longos espaços temporais, reunindo-os como continuidades e equilíbrios permanentes, formando, assim, a maneira usual de fixar as lembranças seculares e milenares. É uma história contada a partir do enfoque temporal e que explica as diferenças que aparecem nos longos períodos como causa do processo de evolução, evidenciando, desse modo, a origem dos fatos (FOUCAULT, 2002), como pude perceber nestes excertos:

Quando busco a evolução histórica da supervisão percebo que cada momento vivido pela sociedade, em conseqüência da evolução econômica, social, cultural, política, surge um tipo de mentalidade dominante que se reflete no trabalho do supervisor. (Livro A, p. 36)

[...] de uma perspectiva meramente funcionalista [...] se encaminha para uma perspectiva crítica, interveniente, emancipatória, baseada na concepção do professor como intelectual e como parte de um coletivo responsável. (Livro C, p. 30)

No entanto, o modo como lemos a questão histórica, atualmente, difere do exposto acima. Considerando o passado como fatos historicamente construídos, que vivemos sem referências predeterminadas, mas imersos em uma teia de significações, não olharemos a história da supervisão como se ela tivesse uma origem, um ponto fixo de onde sua trajetória partiu e tampouco como se sua história tivesse uma evolução contínua e gradual. Aproximamo-nos, assim, do conceito de história geral ou história do presente que Foucault desenvolve a partir da ideia nietzscheana de história vista de baixo:

A história 'efetiva' [geral], lança seus olhares ao que está próximo [...] ela perscruta as decadências; e se afronta outras épocas é com a suspeita - não rancorosa, mas alegre - de uma agitação bárbara e inconfessável. Ela não teme 
olhar para baixo. Mas olha do alto, mergulhando para apreender as perspectivas, desdobrar as dispersões e as diferenças, deixar a cada coisa sua medida e sua intensidade (FOUCAULT, 1986, p. 29).

É uma história vista de baixo por considerar elementos não oficializados, isto é, por considerar elementos que escapam à história global. Destacamos alguns desses elementos que fizeram sentido para nós e selecionamos para analisá-los, na tentativa de entender como os saberes da supervisão escolar foram se construindo e se transformando. A história do presente é uma história que volta ao passado para entender o presente, sem, no entanto, buscar a verdadeira história da supervisão, mas problematizar alguns discursos que vêm constituindo a supervisão na contemporaneidade. Para chegar a esse objetivo, precisamos ir à contramão das estabilidades do corpus discursivo, para organizá-lo de outros modos, problematizando a ideia de progresso e evolução contada na história da supervisão.

Não mais para fixar memórias, a história do presente é feita para estabelecer sentidos - movimento inverso ao da história global. Procuramos aqui, pois, marcar, firmar e delimitar outros sentidos para os fatos históricos da supervisão.

De agora em diante, o problema é constituir séries: definir para cada uma seus elementos, fixar-lhes os limites, descobrir o tipo de relações que lhe é específico, [...] descrever as relações entre as diferentes séries, para constituir, assim, séries de séries. (FOUCAULT, 2002, p. 8-9)

É em busca das diferentes séries ou das séries de séries que interrompemos o curso da história da supervisão trazida nos livros analisados. Contar a história desse jeito não é encerrar uma trajetória ou desfazer-se do que já se tem, mas é formar outro ponto de vista dentro do emaranhado de discursos que a história global pode provocar. Diante da continuidade de uma série linear para a história da supervisão escolar presente no corpus discursivo, identificamos uma regularidade nos ditos: a recorrência da história global narrada pelos quatro livros que neste estudo estão sob análise.

Foi nesse sentido que organizamos alguns ditos da história da supervisão, entendendo-os como narração histórica linear da supervisão escolar. Isso porque, ao lermos o material de análise, em sua grande maio- 
ria, a ação supervisora é contada como uma prática que iniciou com determinada ênfase e que foi evoluindo ao longo de sua trajetória:

Poucas práticas profissionais terão pago um tributo tão alto às condições do tempo em que começaram a se desenvolver no Brasil tal como ocorreu com a supervisão escolar. (Livro B, p. 93)

A revisão dessa ação [supervisora] consistiu num processo de desestruturação da atividade supervisora, na medida em que posições tradicionais foram sendo questionadas e em seu lugar outras foram surgindo. (Livro B, p. 10)

Ao organizar os excertos deste texto, percebemos que as posições tradicionais, isto é, as primeiras ações dos supervisores são marcadas com tons de repulsa e negação, como um passado de que agora se tem vergonha de lembrar e que, por isso, precisa ser esquecido. Assim, é apresentada a Teoria Tradicional do currículo, que se constituiu no período da industrialização e da urbanização da sociedade (MOREIRA; SILVA, 2005).

Buscando a semelhança do sistema educacional com o empresarial - no sentido de sua eficiência produtiva -, cria-se um currículo voltado para as questões técnicas do ensino. Essas evidenciam o que e o como ensinar, derivando daí o surgimento de materiais didáticos, métodos e equipamentos voltados para o aperfeiçoamento do trabalho docente. A escola funcionava como em um chão de fábrica: especificavam os "objetivos, procedimentos e métodos para a obtenção dos resultados que [poderiam] ser precisamente mensurados" (SILVA, 2005, p. 12). Também em nome da eficiência, criam-se outras funções dentro do sistema educacional, entre elas a supervisão, responsável pelo planejamento e pelo controle das atividades pedagógicas, a fim de evitar os desvios das metas preestabelecidas (SILVA, 2005), tal como mostram os excertos:

No primeiro momento de sua história, a supervisão ocupava-se, unicamente, do ensino primário. Tinha a competência de inspeção, encarregada de fiscalizar o prédio escolar, a freqüência de alunos e professores. (Livro A, p. 40)

A característica desta etapa [o início do trabalho da supervisão escolar] é determinar, linear e doutrinariamente, quais os procedimentos que deve ter o supervisor, denominado, à época, coordenador pedagógico, no exercício da função de controlar e acompanhar o trabalho do professor. (Livro A, p. 4) 
Visando à efetivação do currículo tradicional, os esforços dos supervisores se direcionam para determinar o que e como o ensino deve acontecer, seguindo a tarefa de acompanhar sistematicamente o trabalho docente. Em função disso, a ação supervisora envolve-se numa esfera na qual o controle e a fiscalização das questões pedagógicas ganham bastante evidência, características essas que a história contada no corpus discursivo sobre a supervisão escolar deseja hoje esquecer.

Diferentemente desse início, que busca incessantemente ser esquecido, a continuidade da história da supervisão é contada com orgulho nos livros analisados, enfatizando nos ditos a evolução que o trabalho dos supervisores conseguiu alcançar. Isso porque, na tentativa de romper com o caráter tecnicista da educação, surgem novos estudos sobre o currículo escolar, resultando nas Teorias Críticas da educação. Agora, com caráter político, o currículo passa a ser entendido como uma área contestada, uma arena política e não mais como uma forma neutra de transmissão de conhecimentos (MOREIRA; SILVA, 2005.).

Por meio de questões sobre a ideologia, a cultura e o poder, a desigualdade em educação é colocada no centro das preocupações dos teóricos desse campo, por meio de ideias como: escola como local de reprodução e manutenção das classes sociais; superação da cultura unitária como conteúdo a ser transmitido de geração em geração; e, pela primeira vez, as discussões sobre poder aparecem nos textos curriculares. Um poder visto através de uma relação hierárquica e centralizada em uma instituição, no governo em uma pessoa, dividindo os grupos sociais. Um poder visto como algo a ser combatido e transformado. Dessa forma, as Teorias Críticas não se preocupam com o como o currículo deve ser, mas o que ele far. (SILVA, 2005, grifo do autor).

Essa análise, tendo como base as questões econômicas da sociedade dividida em classes, traz a ideia de poder como algo fixo e hierarquizado, como uma relação profundamente negativa entre opressores/oprimidos, dominantes/dominados. Nesse sentido, toda relação arbitrária que leva à subordinação de alguém é entendida como uma coerção, uma vez que reprime e encerra a ação do outro e que, por isso, deve ser superada. É nesse sentido também que as Teorias Críticas, movidas pela politização do currículo, exaltam seu trabalho em direção à liberdade e à conscientização dos sujeitos que passam pelo sistema educacional. Em outras palavras, são o saber e a consciência que garantirão a libertação da condição 
de oprimido desses sujeitos. No lugar de um currículo que reprime, coloca-se outro que propõe a consciência e a liberdade.

A supervisão escolar anunciada no corpus discursivo, imersa nessa esfera política, apresenta-se de forma diferente do que na Teoria Tradicional. Denominando-se como "renovada" (Livro A, B, C e D), desfaz-se da estratégia de controlar o trabalho docente, aliando-se, agora, aos professores para, juntos, encontrarem a melhor alternativa para o trabalho em sala de aula:

O supervisor tem por função, entre outras ações, acompanhar a classe do professor, superando os impasses de significados negativos impostos à palavra supervisão ou a uma certa prática de supervisão, transcendendo as concepções de controle, poder, coordenação, assessoramento. O supervisor passa a se ocupar com o campo do ensinar e do aprender. (Livro A, p. 130)

O trabalho do professor abre o espaço e indica o objeto de ação/reflexão, ou de reflexão/ação para a ação supervisora. Dessa forma [...] contraria a concepção de uma ação supervisora centrada no controle puro e simples do trabalho do professor e em seu lugar apresenta-se como uma possibilidade de ação conjunta voltada para a produção do trabalho do professor em sala de aula, como sujeito que ensina-aprende. (Livro A, p. 156)

Do ponto de vista da história global, como caracteriza Foucault, a história da supervisão de que o corpus discursivo vem compor marca a questão temporal e linear do supervisor. Como podemos ver, a supervisão é narrada como um trabalho que evoluiu de uma ação "controladora" para uma "ação conjunta com os professores", marcando, assim, duas fases diferentes dessa função, evidenciando uma ruptura na forma como o trabalho da supervisão é realizado. Olhando, pois, para esses ditos, não os consideramos como se acontecessem em um desenvolvimento gradativo, como um movimento marcado por rupturas que fizeram a supervisão evoluir em seu trabalho. Apoiadas no referencial deste texto, não consideramos essa narração histórica como discursos que se fundam no sujeito falante, sendo aperfeiçoados no momento em que alguém descobrir um jeito novo e melhor de fazer supervisão. Nós os consideramos como invenções que se tornaram verdades e que, para atingir esse status, isto é, para que sejam aceitas como tais, dependem e se subordinam a uma ordem bem mais ampla do que o discurso educacional. Foucault chama essa ordem mais ampla de "episteme", que consiste em um "conjunto de 
condições, de princípios, de enunciados e regras que regem sua distribuição, que funcionam como condição de possibilidade para que algo seja pensado em uma determinada época" (VEIGA-NETO, 2003, p. 115).

As verdades que o mundo aceita e reproduz são assim legitimadas porque pertencem a esse "conjunto de condições", a uma lógica de pensamento que integra alguns discursos e proíbe outros. O que é falado na supervisão escolar pertence a um conjunto de regras que permite e que faz funcionar tais discursos, imprimindo a eles sentido de verdade, segurança, estabilidade, entre outros. Desse modo, tantas outras práticas são proibidas porque não são reconhecidas em sua positividade ${ }^{3}$, não se ajustam à episteme e, por isso, não são formalizadas e oficializadas por ela. "Por episteme entende-se, na verdade, o conjunto das relações que podem unir, em uma dada época, as práticas discursivas que dão lugar a figuras epistemológicas, a ciências, eventualmente a sistemas formalizados" (FOUCAULT, 2002, p. 217, grifo do autor).

É a episteme da época, no nosso caso, a Episteme Moderna, que diz o que conta como verdadeiro nos diferentes campos de saber. É ela que delimita o que é possível falar, pensar e fazer na supervisão escolar. Foi ela que autorizou os discursos presentes no corpus discursivo desta pesquisa, produzindo a ordem discursiva da supervisão escolar na contemporaneidade.

$\mathrm{Na}$ tentativa de visualizar a narração linear da história da supervisão, de poder mostrar que não houve ruptura evolutiva em seu trabalho, mas diferentes discursos que circulam sobre o solo da Episteme Moderna, trazemos mais alguns excertos do material de análise que contribuem para entendermos a supervisão como um campo do saber que, ao longo de sua história - e na atualidade -, guarda várias marcas de estratégias de regulação do trabalho docente:

[...] Para uma sociedade controlada, uma educação controladora; para uma educação controladora, um supervisor controlador e também controlado. (Livro B, p. 93)

O supervisor, tomando como objeto de seu trabalho a produção do professor, afasta-se da atuação linear, hierarquizada, burocrática que vem sendo questionada por educadores e passa a contribuir para um desempenho docente mais qualificado. (Livro B, p. 31)

Supervisão será sempre uma forma de verificação, de avaliação, mas de verificação e de avaliação com a finalidade de prestar assistência e colaboração. (Livro A, p. 43) 
[...] o supervisor não é mais aquele sujeito que possui um 'superpoder' de assessorar, acompanhar, controlar e avaliar o trabalho que os professores realizam nas escolas, mas aquele que constrói com os professores seu trabalho diário. (Livro A, p. 83, grifo do autor)

Assim, o supervisor torna-se um parceiro político-pedagógico do professor que contribui para integrar e desintegrar, organizar e desorganizar o pensamento do professor num movimento de participação continuada, no qual os saberes e os conhecimentos se confrontam. (Livro B, p. 32)

Essas ideias aparecem nos textos como pertencentes a fases diferentes do trabalho da supervisão. No entanto, aproximando-as e estabelecendo algumas relações, é possível fazer certos questionamentos, como: a escola se desfez, atualmente, do papel de mudar a sociedade? A presença do/a supervisor/a na escola ainda se justifica pela garantia de efetivar a mudança da sociedade? Sendo assim, o/a supervisor/a tem seu trabalho regulado pelos cargos superiores e mantém a mesma regulação com os professores pelos quais é responsável? Prestar assistência e colaboração, acompanhar a produção dos professores e ser um "parceiro político-pedagógico" não se aproxima da ideia de manter uma atuação supervisora linear e hierarquizada? Construindo com os professores seu trabalho diário, não deverá o supervisor regular o trabalho docente para orientar seu grupo de colegas?

Ao fazer tais perguntas, pensamos estar colocando em xeque o divisor de águas do qual a supervisão escolar narrada no corpus discursivo da pesquisa demonstra ter muito orgulho: a despedida do caráter controlador. Vinculado ao que as Teorias Críticas postulam, os demais ditos aparecem como se tivessem uma nova roupagem, indicando uma ação supervisora mais humilde em seus posicionamentos, agora com o supervisor sendo "parceiro político-pedagógico do professor" (Livro B, p. 32). Ainda que os excertos mostrem recorrente e insistentemente essa visão, queremos problematizar aqui como a regulação está ainda presente na ação supervisora. Em momento algum os textos indicam que o trabalho do/a supervisor/a é ou deve ser feito dessa forma. Pelo contrário, após superar esse período vergonhoso, a supervisão encontra seu verdadeiro sentido, aliando-se aos professores. "Visto globalmente, pode-se ter a impressão de que aí, praticamente não se fala em [controle]" (FOUCAULT, 2006c, p. 34). Ao analisarmos, porém, as ações que o/a supervisor/a está agora autorizado a desempenhar, constatamos que ele existe: silencioso, mas direto e contínuo. 
[...] o supervisor tem seu objeto específico de trabalho - a produção do professor - evidenciado na aprendizagem do aluno. [...] As experiências e os estudos de aprofundamento realizados pelo supervisor é que irão desencadear um trabalho, visando à investigação do desempenho do professor no dia-a-dia da escola. Nessa investigação, o supervisor produz interrogações, faz afirmações, confronta idéias, tentando descobrir a melhor maneira de o professor ensinar e aprender em determinada classe de alunos. (Livro A, p. 153 e 154, grifos meus)

[...] a supervisão do conteúdo implica a supervisão de currículo e programas, contando com a participação e com oportunidades de estudo e integração dos professores promovidos pelo supervisor, observando-se a atualização do conhecimento e dos referentes do contexto, das normas e da didática. (Livro C, p. 64, grifos meus)

"Prestando assistência e colaboração", "construindo com os professores seu trabalho diário", "investigando seus desempenhos", "dizendo a melhor forma de realizar seu trabalho" e "oportunizando momentos de formação continuada" são entendidas como ações que indicam que a regulação sobre o corpo docente não está ausente também nessa fase renovada da supervisão. $\mathrm{O} / \mathrm{a}$ supervisor/a continua regulando o trabalho dos professores, porém com ações menos autoritárias, usando palavras mais amenas e estabelecendo o que chama de parceria com sua equipe docente.

Essa característica do/a supervisor/a o/a acompanha desde seu ingresso no quadro de funcionários das escolas. A diferença talvez esteja na forma como esse controle é visto. Não o entendo como um "controle" negativo (Livro A, B, C e D), que reprime os que são obrigados a se submeter, mas um controle que encontra positividade (e por isso é legitimado no espaço escolar), porque é útil para a melhoria do trabalho docente. É uma vigilância voltada à produção da ação docente, que faz com que os professores trabalhem e trabalhem de forma correta e, assim, alcancem o que a supervisão/escola/sociedade espera deles. Por isso, poderia dizer que o polêmico controle que a história global da supervisão vem narrando, ora como parte do trabalho do/a supervisor/a ora como ideia superada no campo de saber da supervisão escolar, é visto aqui como sinônimo de produtividade.

Em meio aos discursos sobre controle da ação supervisora, encontramos alguns - poucos - ditos que compreendem essa função como 
reguladora. Entre os vários artigos que abordam a história da supervisão escolar nos livros analisados, apenas um deles reconhece a questão do controle do/a supervisor/a sobre o trabalho docente:

[...] percebe-se a necessidade da prática profissional da supervisão educacional como um trabalho de coordenação e 'controle' da prática educativa, a fim de assegurar os princípios e as finalidades da educação [...]. (Livro C, p. 86, grifo do autor)

Solidariedade é o espírito de um novo 'controle' a ser exercido pela prática da supervisão que o profissional da educação necessita desenvolver. (Livro C, p. 97, grifo do autor)

Necessita, então, o profissional da educação exercer o controle em suas atividades profissionais? Sim, mais do que nunca. "Esse controle terá, portanto, outra qualidade, que não é a estabelecida pelo estatuto autoritário, tampouco se refere à qualidade total, mas, sim, a uma qualidade social que se encontra no exercício da cidadania e com ela se identifica - princípio constitucional, que a lei 9.394/96 exara no seu art. 20." (Livro C, p. 98, grifo meu)

Ao contrário dos outros excertos, nesses o controle é reconhecido como parte integrante da ação supervisora, aparecendo como uma forma de garantir os objetivos do sistema educacional, reforçando, assim, o vínculo entre supervisão escolar, escola e sociedade. Esta, visando à formação de sujeitos disciplinados, faz uso da instituição escolar para alcançar seus princípios e, nesse processo, o/a supervisor/a apresenta-se como uma peça ideal e fundamental dentro desta grande maquinaria disciplinar.

Outra questão que merece destaque é o cuidado com que esse controle é anunciado: "um novo controle" baseado na "solidariedade" do/a supervisor/a, e não no "estatuto autoritário" nem na "qualidade total". Para que o controle seja aceito no discurso da supervisão escolar, ele é imediatamente desvinculado do caráter repressor relacionado à primeira fase da supervisão para ganhar outro sentido na fase renovada. Esse cuidado com a palavra traz consigo um tom de repúdio que as Teorias Críticas mostram frente ao que pode ameaçar a liberdade e a conscientização, nesse caso, da equipe docente. Assim, parece-nos evidente que, para ser aceito nessa ordem discursiva, os discursos da supervisão escolar precisam ter uma roupagem que não intimide os sujeitos que a eles se submetem, tal como mostram os excertos anteriores. 
Contudo, mesmo com esses excertos divergindo dos demais, percebemos que a ação reguladora do trabalho da supervisão, de uma forma ou de outra, ainda está presente em sua função. Queremos destacar aqui o que viemos problematizando neste texto: a supervisão escolar é uma estratégia de ação que coloca em funcionamento a regulação do trabalho docente.

Com isso, ousamos romper a história global e linear da supervisão para formar outros cruzamentos e reforçar a ideia de que a evolução da ação supervisora não aconteceu. Entendemos que os dados analisados indicam alterações no modo como a supervisão escolar vem encaminhando seu trabalho, porém, conforme a análise dos mesmos, o controle, isto é, a regulação, a vigilância sobre o trabalho dos professores, não cessa de aparecer. Acreditamos que isso aconteça por estar vinculado ao fato de a supervisão escolar atender à escola moderna, a qual se constitui como uma das instituições da sociedade que atua na produção de sujeitos disciplinados e úteis. Por atender à escola moderna, atende também à Episteme Moderna, essa ordem maior que determina o que entra ou não, neste caso, no discurso da educação.

$\mathrm{Na}$ Episteme Moderna, as Ciências aparecem como a grande "politica geral da verdade" (FOUCAULT, 1986, p. 12, grifo do autor), constituídas para acolher e fazer funcionar alguns discursos como verdadeiros. É por meio das ciências que o homem busca conhecer a si mesmo como objeto do conhecimento e que, por isso, acaba por desenvolver uma série de discursos sobre sua própria maneira de ser e de viver.

Assim, são as Ciências Humanas que produzem as verdades sobre a educação e suas especificidades. Entre elas, encontram-se os discursos sobre a supervisão escolar que também criam um campo de saber sobre o homem, neste caso, sobre o fazer docente, buscando seu constante aprimoramento e, por isso, a regulação dos professores. Desse modo, tanto na fase de "controle" (Livros A, B, C e D) quanto na fase "renovada" (Livros A, B, C e D), a supervisão escolar realiza seu trabalho na mesma direção, sem romper com a episteme vigente.

A essa altura, voltamos a dizer que, ainda que as características do trabalho desempenhado pelos/as supervisores/as tenham apresentado alterações, os efeitos da ação supervisora permaneceram os mesmos. Isso equivale a comentar que há olhares diferentes da supervisão escolar ao longo de sua trajetória, porém ambos dentro da Episteme Moderna, uma 
vez que atendem à produção de sujeitos disciplinados e úteis, princípios fundamentais dessa lógica de pensamento vigente.

Esses olhares da supervisão escolar são analisados aqui como diferentes ordens do discurso educacional. Ordens que encontraram legitimidade por estarem, em determinado momento, consideradas verdadeiras. Lembrando do exposto no início do texto, os olhares diferentes do campo de saber em questão dizem respeito à Teoria Tradicional e às Teorias Críticas do currículo.

Há algum tempo, o que estava "no verdadeiro" eram as técnicas e métodos utilizados nas aulas, o rigor e a eficiência no processo de ensino e a supervisão atuando como base controladora e fiscalizadora do trabalho docente (Livros A, B, C e D). Nas Teorias Críticas, por sua vez, o que está "no verdadeiro" é a conscientização dos sujeitos por meio do currículo para sua futura autonomia e liberdade, com a supervisão colocada como parceira dos professores (Livro A, B, C e D). Sendo assim, não é qualquer coisa que pode ser dita entre os discursos da educação. É preciso estar na ordem, "no verdadeiro, na polícia discursiva para que os discursos sejam aceitos. Não nos encontramos no verdadeiro, senão obedecendo uma polícia discursiva que devemos reativar em cada um de nossos discursos" (FOUCAULT, 2006a, p. 35, grifo do autor). Em função dessa polícia discursiva é que se entende a Teoria Tradicional e as Teorias Críticas como as ordens do discurso contadas no material de análise, exatamente por terem, cada uma, em sua época, o conteúdo de verdade do discurso educacional.

Em suma, a história da supervisão escolar não é progressista, como é contada nos dados analisados, pois não houve evolução em seu trabalho. Houve, sim, diferentes ordens do discurso se produzindo dentro de um mesmo solo epistêmico, que fez e faz funcionar a supervisão como um campo do saber que continua a criar estratégias para a regulação do professorado, com outras roupagens, mas continua a produzir e fabricar sujeitos dóceis e úteis para a escola moderna.

Com esse entendimento de regulação do trabalho docente e com as características da ação supervisora que apresentamos, percebemos as possíveis articulações dessa análise com o que Foucault denominou "poder disciplinar" (2006b). Acreditamos que esse poder está presente tanto na primeira fase histórica da supervisão quanto na fase dita renovada. 


\section{Supervisão escolar como estratégia de ação do poder disciplinar}

Procurando problematizar a questão da supervisão escolar como ação reguladora do trabalho docente, aproximamos essa análise a um tipo específico de poder, presente na Episteme Moderna: o "poder disciplinar". Em suas palavras:

O poder disciplinar é com efeito um poder que, em vez de se apropriar e de retirar, tem como função maior 'adestrar'; ou sem dúvida adestrar para retirar e se apropriar ainda mais e melhor. [...] Adestra as multidões confusas, móveis, inúteis de corpos e forças para uma multiplicidade de elementos individuais [...]. A disciplina 'fabrica' indivíduos; ela é a técnica específica de um poder que toma os indivíduos ao mesmo tempo como objetos e como instrumentos de seu exercício. Não é um poder triunfante que, a partir de seu próprio excesso, pode-se fiar em seu superpoderio; é um poder modesto, desconfiado, que funciona a modo de uma economia calculada, mas permanente (FOUCAULT, 2006b, p. 143).

Nossa sociedade está organizada dentro desse sistema e nossa vida é, constantemente, atravessada por esse poder, que captura todos nós, observando, regulando e modelando nosso jeito de ser. Esse poder, discreto, porém muito eficaz, "fabrica e adestra" os sujeitos para o que a sociedade espera deles: ordem e progresso, características vistas aqui como necessárias para a regulação de cada indivíduo. É um poder que desloca o brilho dos espetáculos da Época Clássica para focar a totalidade dos sujeitos e, ao mesmo tempo, a individualidade de cada um, vigiando e regulando suas vidas. Não mais se sustenta pelo vigor dos que o impõe: sua ênfase está na aplicação do poder a todos os sujeitos que compõem a "sociedade disciplinar" (FOUCAULT, 2006b).

É um poder que atua na continuidade, na permanência, em uma constante, porém sutil marcação das condutas no interior de cada um dos indivíduos. Como resultado do poder disciplinar, Foucault apresenta o sujeito provido de um corpo "dócil", que, sendo fabricado e adestrado, transforma-se em objeto a serviço da sociedade. "É dócil um corpo que pode ser submetido, que pode ser utilizado, que pode ser transformado e aperfeiçoado" (Ibid, p. 118).

Com a fabricação desse ideal de sujeito, constitui-se também a sociedade disciplinar composta por instituições que mobilizam o poder disciplinar. Assim, essa sociedade retém os sujeitos para si, impondo-lhes 
"limitações, proibições ou obrigações" (FOUCAULT, 2006b, p. 118). Entre essas instituições, encontra-se a escola, com toda a sua estrutura física e seus saberes pedagógicos, investindo, permanentemente, no conhecimento e, por isso, na regulação sobre todos os que nela se encontram.

Da mesma forma que a sociedade, a escola atua na formação/ fabricação de sujeitos disciplinados e, gradativamente, autodisciplinados, para agirem de maneira ordenada e correta ao longo da vida. Assim, escola e sociedade andam em harmonia perfeita: a primeira contribuindo com a segunda, e ambas com características marcadamente modernas, atendendo à mesma episteme.

Implicadas diretamente com os ideais da escola/sociedade, percebemos que a supervisão escolar aparece como uma estratégia que também coloca em prática o poder disciplinar. Atuando junto aos professores, o/a supervisor/a vigia e corrige o trabalho destes, mantendo-os sob constante visibilidade. É com essas ideias que aprofundamos a análise sobre a ação supervisora, tentando aproximá-la dos instrumentos sobre os quais o poder disciplinar age no interior dos sujeitos, especificamente, nesse caso, sobre o corpo docente: "vigilância hierárquica, sanção normalizadora e exame” (FOUCAULT, 2006b, p. 143).

\subsection{Vigilância hierárquica: 0 olhar que disciplina}

Segundo Foucault (FOUCAULT, 2006b, p. 143), a conduta disciplinar que se espera dos sujeitos é perfeitamente viável através do olhar que vigia; um olhar discreto que coloca em evidência permanente os que são vigiados. Esse olhar vigilante que atua sobre as pessoas é lembrado aqui como aquele que o/a supervisor/a escolar tem sobre o corpo docente. Por estar legitimado a acompanhar e investigar o trabalho dos professores, esse olhar do/a supervisor/a sobre sua equipe é considerado, neste estudo, como disciplinar, que direciona as condutas e ações dos professores. Mesmo denominando-se "parceiro político-pedagógico do professor" (Livro B, p. 32), seu trabalho não deixa de manter a característica de ser um constante vigia, como mostra o excerto a seguir, que discorre sobre como o/a supervisor/a pode contribuir para o trabalho dos professores:

$[\cdots]$

Conversando diariamente com os professores e procurando saber quais são suas dificuldades; 
orientando e incentivando o desempenho individual e grupal dos professores; acompanhando e avaliando o professor em relação ao que faz e como faz o seu próprio trabalho;

assessorando o trabalho do professor (transmitindo sugestões de atividades);

$[\ldots]$

revisando modelos de provas bimestrais; [...]

pesquisando as formas como os professores trabalham; [...

elogiando o que é positivo e esclarecendo o que considera negativo;

repensando idéias;[...]. (Livro A, 102 e 103)

Intensificando seu olhar sobre o corpo docente e agindo por meio da observação constante dos professores, percebemos uma forte vinculação do trabalho do/a supervisor/a escolar à "vigilância hierárquica", a fim de realizar suas ações junto aos docentes, ainda que essa característica não esteja expressa diretamente no corpus discursivo desta pesquisa.

Ao pensar dessa forma, a escola acaba por constituir-se também como uma instituição que produz esse/a vigia, uma vez que precisa dele/a para direcionar o trabalho dos professores com vistas ao agir pedagógico correto. Cumprindo sua função na escola, o/a supervisor/a faz uso dessa vigilância para o funcionamento correto e produtivo do trabalho docente. Observando, investigando, orientando, elogiando, avaliando, revisando a ação dos professores, entre outras funções que o/a supervisor/a desempenha, ele/a regula a ação dos colegas, estabelecendo o olhar constante sobre a forma como eles trabalham.

É interessante observar que a vigilância hierárquica exercida pelo/a supervisor/a sobre os professores também recai sobre os próprios supervisores, no que diz respeito ao cumprimento das exigências dos órgãos superiores acima deles, tal como secretarias municipais e mantenedoras. Toda essa estrutura reguladora remete à ideia de uma rede de vigilância colocada em ação por todos os que a constituem, formando o que Foucault chama de "maquinaria de controle". Nas palavras do autor:

As instituições disciplinares produziram uma maquinaria de controle que funcionou como um microscópio do comportamento; as divisões tênues e analíticas por elas realizadas formaram, em torno dos homens, um aparelho de observação, de registro e de treinamento (FOUCAULT, 2006b, p. 145).

É importante destacar, ainda, que a maquinaria de controle de que nos fala o filósofo não é entendida como um poder que funciona por- 
que reprime os que por ele são capturados. Tal como iniciamos a discussão referente ao poder disciplinar, ele atravessa todos que fazem parte, neste caso, da escola. "Se é verdade que sua organização piramidal lhe dá um chefe, é o aparelho inteiro que produz poder e distribui os indivíduos nesse campo permanente e contínuo" (FOUCAULT, 2006b, p. 148) [grifos do autor].

Por isso, o poder que aqui é analisado na relação entre o/a supervisor/a escolar e os professores é entendido como uma relação de forças de ambos os segmentos. Se o/a supervisor/a atua como um vigia é porque essa ação encontra legitimidade por parte não somente dos órgãos superiores de ensino, mas também de seus colegas da escola, sendo assim um poder que é "auto-sustentado" (FOUCAULT, 2006b, p. 148) por seus próprios participantes.

\subsection{Sanção normalizadora: 0 olhar que corrige}

Além da vigilância constante dos e sobre os sujeitos, o poder disciplinar preocupa-se com as condutas que fogem da regra estabelecida, com os desvios que podem acontecer, dificultando o alcance do resultado desejado. Para evitar esses desvios e reforçar as atitudes corretas dos sujeitos, o poder disciplinar coloca também em ação o que Foucault chama de "sanção normalizadora", isto é, micropunições que buscam corrigir as condutas inadequadas por meio de pequenos "castigos", tal como mostra o filósofo:

\footnotetext{
$\mathrm{Na}$ oficina, na escola, no exército funciona como repressora toda uma micropenalidade do tempo (atrasos, ausências, interrupções das tarefas), da atividade (desatenção, negligência, falta de zelo), da maneira de ser (grosseria, desobediência), dos discursos (tagarelice, insolência), do corpo (atitudes 'incorretas', gestos não conformes, sujeira), da sexualidade (imodéstia, indecência) (FOUCAULT, 2006b, p. 149).
}

Trata-se, pois, do estabelecimento de regras, de um programa, de um regulamento, de uma ordenação que visa a corrigir os comportamentos que fogem da disciplina, de um castigo para quem não age em conformidade com o que é exigido sutilmente. Passando pelas micropenalidades, o poder disciplinar faz com que os sujeitos exercitem a correção de suas condutas, reparando e se arrependendo de seus erros. Essa estratégia reguladora aparece como a intenção de inculcar nos indivíduos a nãorepetição das mesmas atitudes inadequadas. 
A escola, como uma instituição que atende e faz funcionar o poder disciplinar, possui também suas micropunições para evitar ou, se necessário, corrigir os desvios. Restringindo-nos ao que se refere diretamente aos professores, citamos algumas delas: livro ponto, caderno de chamada, Regimento Escolar e relatórios de estágio probatório. Essas regras descrevem as atitudes que a equipe docente pode e não pode realizar, isto é, suas obrigações e, ao mesmo tempo, suas proibições.

Diante desses regulamentos, a escola expõe o tipo de conduta que se espera dos professores, assim como eles aceitam tal ordenamento, na medida em que internalizam essas mesmas condutas. Tal como Foucault (2006b) descreve, a sanção normalizadora, as micropenalidades (que traço uma relação direta nesta pesquisa com o trabalho dos professores nas escolas), acabam por constituir uma classificação entre os professores, separando os bons dos maus, os mais obedientes dos mais rebeldes/resistentes, os mais empenhados dos menos criativos e assim por diante. É uma classificação feita a partir das pequenas punições, que estabelece uma hierarquia entre os docentes, conforme o comportamento de cada um.

Em suma, é uma estratégia que "exerce sobre [os professores] uma pressão constante” (FOUCAULT, 2006b, p. 152), a qual homogeneíza todos no que diz respeito às regras exigidas pela escola e internalizadas pelos docentes. Ao mesmo tempo, individualiza cada professor, na medida em que mede o esforço de cada um e, se necessário, corrige seus desvios.

Diante dessa exposição, a supervisão escolar entra aqui como uma função que viabiliza perfeitamente esses efeitos da sanção normalizadora sobre os professores. Ela se mostra autorizada a acompanhar o cumprimento das responsabilidades do corpo docente, assim como a redirecionar/punir suas ações, quando não estiverem em conformidade com o que lhes é exigido. A supervisão escolar, evitando e corrigindo desvios, classificando os professores com base no desempenho de cada um, "compara, diferencia, hierarquiza, homogeneíza, exclui. Em uma palavra, ela normaliza" (FOUCAULT, 2006b, p. 153, grifo do autor), por meio de suas estratégias de regulação do trabalho docente.

Por outro lado, é interessante observar que o/a supervisor/a também é submetido aos mesmos efeitos desse instrumento disciplinar, novamente diante das exigências dos órgãos que lhe são superiores. As 
palavras a seguir mostram bem essa afirmação: [o supervisor] não se submetendo às determinações e às expectativas do sistema, ele é afastado da função (Livro B, p. 118). A ameaça do/a supervisor/a perder seu cargo por não cumprir o que é exigido pelas instâncias acima dele/a faz pensar que a sanção normalizadora também age com pressão constante sob a pessoa que atua como supervisor escolar. Da mesma forma que os professores, o/a supervisor/a também atende a um conjunto de micropenalidades que evitam, corrigem e punem suas ações inadequadas. Assim também ocorre a classificação hierárquica entre tais indivíduos, indicando e separando os bons dos maus supervisores.

\subsection{Exame: 0 olhar que normaliza}

Atuando na fabricação de sujeitos dóceis e úteis, Foucault descreve o "exame", o último instrumento do poder disciplinar, sendo ele um procedimento que combina os dois primeiros analisados: a vigilância hierárquica, que observa permanentemente, e a sanção normalizadora, que regula.

O exame combina as técnicas da hierarquia que vigia e as da sanção que normaliza. É um controle normalizante, uma vigilância que permite qualificar, classificar e punir. Estabelece sobre os indivíduos uma visibilidade através da qual eles são diferenciados e sancionados (FOUCAULT, 2006b, p. 154).

Com esse instrumento do poder disciplinar, percebemos o/a supervisor/a escolar como a pessoa autorizada a estabelecer sobre os professores um campo de visibilidade que permite corrigir, direcionar, comparar, individualizar e homogeneizar, ao mesmo tempo, o corpo docente pelo qual é responsável. É essa visibilidade que faz do/a supervisor/a um/a constante examinador/a:

[...] o supervisor atua como uma espécie de par de olhos para focar, com os professores, o contexto no qual trabalham, por que trabalham, como trabalham e para quem trabalham. [...] Acredito que o supervisor, por intermédio de atividades baseadas na pesquisa do trabalho realizado na dia-a-dia da escola, identifica os espaços que pode ocupar ao problematizar o trabalho do professor de sala de aula (Livro A, p. 158, grifos do autor).

Trabalhando como um "par de olhos", professores e supervisores autorizam e legitimam sua atuação como um vigilante que busca estar sempre a par do trabalho dos professores: dificuldades que enfrentam, sua 
função na escola, formas como encaminham a aprendizagem dos estudantes, resultados alcançados, entre outros. Até mesmo a "pesquisa do trabalho realizado no dia-a-dia da escola" indica o poder disciplinar atuando por meio do olhar vigilante do supervisor. Pensando nesse olhar que vigia, é interessante comentar aqui o procedimento do/a supervisor/a frente às ações inadequadas de sua equipe docente. Quanto a isso, em nenhum momento os livros analisados trazem para discussão o que fazer, por exemplo, quando os professores não encaminham seu trabalho conforme o esperado, o que fazer com os colegas mais resistentes ou com os maus professores em relação ao seu desempenho.

Pelo que os excertos destacados sinalizam, percebemos que se a vigilância exercida pelo/a supervisor/a produz efeitos disciplinares nos professores, essa mesma vigilância está autorizada a corrigir e a punir, isto é, a colocar em ação as micropenalidades comentadas anteriormente. É esse conjunto de vigilância e sanção que normaliza o trabalho docente em que a supervisão escolar atua, também como examinadora constante da sua equipe. É pela pressão constante do olhar hierárquico do/a supervisor/a e por estar autorizado/a a corrigir o que for necessário que mantém os professores disciplinados. Assim é o exame, uma estratégia de captura de professores e supervisores para os fins úteis da educação:

É o fato de ser visto sem cessar, de sempre poder ser visto, que mantém sujeito o indivíduo disciplinar. E o exame é a técnica pela qual o poder, em vez de emitir os sinais de seu poderio, em vez de impor sua marca a seus súditos, capta-os num mecanismo de objetivação (FOUCAULT, 2006b, p. 156).

Com a análise dos três instrumentos do poder disciplinar descritos por Foucault (2006b), buscamos, então, relacioná-los com o trabalho da ação supervisora, agindo na relação entre supervisor/a escolar e professores, produzindo e adestrando esses sujeitos.

Consideramos importante comentar, ainda, uma questão que se faz necessária. Indo na contramão do corpus discursivo deste texto, narramos a supervisão escolar como função que vigia, corrige e regula, a todo o momento, a ação dos professores. Analisando, no entanto, a supervisão com essas características, não o fizemos com interesse de posicioná-la nem para o bem nem para o mal em relação ao corpo docente.

Para alguns, a descrição que fizemos da supervisão escolar pode ser vista como uma ação profundamente negativa, que reprime e mantém 
os professores em situação de classe oprimida. No entanto, não há espaço para tal entendimento neste texto, pois, como diz Foucault, "temos que deixar de descrever sempre os efeitos de poder em termos negativos: ele exclui, reprime, recalca, censura, abstrai, mascara, esconde. Na verdade o poder produz; ele produz realidade, produz campos de objetos e rituais da verdade" (FOUCAULT, 2006b, p. 161, grifos do autor). É justamente essa a intenção da análise: olhar o poder como produtor de verdade.

Nesse sentido, foi chacoalhando as verdades e os discursos da supervisão escolar, em um processo de história linear/global, trazidos nos livros sob análise, que pudemos olhar para alguns dos efeitos desse campo do saber. Assim, problematizamos a história geral e a regulação do fazer e do pensar docente como estratégia da supervisão escolar de organizar o trabalho pedagógico e a constante produção dos professores.

É essa a ideia de produtividade do trabalho docente que justifica a regulação da prática desses mesmos sujeitos, por parte do/a supervisor/a escolar, ainda na fase dita renovada. Ao manter os professores regulados, a supervisão escolar contribui e reforça a fabricação de sujeitos dóceis e úteis, atendendo assim ao que a escola/sociedade espera dos professores: o processo de ensino/aprendizagem eficaz dos estudantes. Isso equivale a fazer a seguinte síntese/relação: supervisão - regulação - disciplina = produção.

Foi procurando descrever a história do presente da supervisão escolar, analisando o corpus discursivo, que percebemos o mesmo solo epistêmico, nas diferentes funções e práticas da ação supervisora, nas duas fases em que são apresentadas. Foi, também, analisando a história da supervisão que interrompemos o curso natural de sua história para estabelecer outras séries, outros sentidos. Foi, ainda, estabelecendo outros sentidos que colocamos sob suspeita a ideia da história linear da supervisão escolar, chegando à problemática da regulação do trabalho docente. Em outras palavras, uma narração histórica que coloca em funcionamento a regulação do professorado; uma história que nada tem de linear, mas que, embora pertencendo a ordens discursivas diferentes, atende a mesma estratégia de ação reguladora. Assim, se, na primeira fase, o/a professor/a era obrigado a seguir as determinações do/a supervisor/a, na fase renova$d a$, ele pode escolher como fazer, ainda que devendo atender à ordem discursiva da educação atual. A regulação permanece.

Como problematizamos, essa regulação é anunciada como uma prática que encontra legitimidade no âmbito educacional. A presença da 
supervisão escolar justifica-se pelas suas ações de acompanhamento, assessoramento, pesquisa e orientação sobre o trabalho de seus próprios colegas. É uma prática autorizada a regular e, por isso mesmo, a disciplinar a ação docente, que, por sua vez, também se justifica pela sociedade disciplinar em que vivemos.

\section{Notas}

${ }^{1}$ Por uma questão metodológica, anunciamos as obras que compuseram o corpus discursivo desta pesquisa: Livro A - MEDINA, Antonia da Silva. Supervisão Escolar da ação exercida à ação repensada. 2 ed. Porto Alegre: AGE, 2002, 167p. Livro B - RANGEL, Mary (Org.). Supervisão Pedagógica: princípios e práticas. 2 ed. Campinas: Papirus, 2001, 102p. Livro C - RANGEL, Mary e SILVA JR, Celestino Alves (Orgs.). Nove olhares sobre a Supervisão Escolar. 4 ed. Campinas: Papirus, 1999, 197p. Livro D - MAIA, Graziela Zambão Abdian. (Org.). Administração \& Supervisão Escolar: questões para o novo milênio. São Paulo: Pioneira, 2003, 118p.

${ }^{2}$ Destacamos os excertos do corpus discursivo grifando-os em itálico.

${ }^{3}$ Entendemos positividade, conforme Foucault, como algo que produz seus efeitos e sentidos em determinada época, traçando suas utilidades no espaço-tempo em que se situa.

${ }^{4}$ O estudo realizado por Foucault na obra citada refere-se à sexualidade e ao sexo. Nosso estudo apresenta outro objeto de análise. Entretanto, problematizando a regulação, percebemos a importante e preciosa obra a ser utilizada para adensar os estudos aqui produzidos.

${ }^{5}$ Nos estudos de Foucault, especialmente a partir dos textos publicados de suas aulas do ano de 1976, no livro intitulado Em defesa da sociedade, o filósofo anuncia outro poder presente em nossa sociedade: o biopoder. Um poder massificante, que direciona suas forças para a população. Com isso, Foucault não invalida o poder disciplinar, mas apresenta outro poder que vem compondo o cenário contemporâneo juntamente com as disciplinas. Em nossa pesquisa, trabalhamos com o conceito de poder disciplinar por perceber a atuação dessa estratégia de regulação no trabalho da ação supervisora. Um poder canalizado para o corpo individual do professorado.

\section{Referências bibliográficas}

CORAZZA, Sandra Mara. Labirintos da pesquisa, diante dos ferrolhos. In: COSTA, Marisa Vorraber. (Org.) Caminhos investigativos: novos olhares na pesquisa em educação. 2 ed. Rio de Janeiro: DP\&A, 2002. p. 105-131.

FOUCAULT, Michel. Microfísica do poder. 6 ed. Rio de Janeiro: Graal, 1986.

FOUCAULT, Michel. Arqueologia do saber. 6 ed. Rio de Janeiro: Forense Universitária, 2002.

FOUCAULT, Michel. $A$ ordem do discurso. 14 ed. São Paulo: Loyola, 2006 a. 
FOUCAULT, Michel. Vigiar e punir: história da violência nas prisões. 31 ed. Petrópolis: Vozes, 2006b.

FOUCAULT, Michel. História da sexualidade I: a vontade de saber. 17 ed. São Paulo: Graal, 2006c.

MOREIRA, Antonio Flávio; SILVA, Tomaz Tadeu da. Sociologia e Teoria Crítica do Currículo: uma introdução. In: MOREIRA, Antonio Flávio; SILVA, Tomaz Tadeu da. (Orgs.). Currículo, cultura e sociedade. 8 ed. São Paulo: Cortez, 2005. p. 7-37.

SILVA, Tomaz Tadeu de. Documentos de Identidade: uma introdução às teorias do currículo. 2 ed. Belo Horizonte: Autêntica, 2005.

VEIGA-NETO, Alfredo. Foucault \& a Educação. Belo Horizonte: Autêntica, 2003.

Endereço para correspondência: Universidade Federal do Rio Grande Instituto de Educação Av. Itália, s/n, Km 08 Campus Carreiros Carreiros $96201-900$ Rio Grande - RS

Data de recebimento: 10/10/2008 Data de aprovação: 10/11/2009 